\title{
Analisis Adopsi Inovasi Teknologi Informasi Menggunakan Innovation and Diffusion Theory (IDT) Pada PPDB Online SMKN 3 Gowa
}

\author{
Ayu Lestari Perdana*1, Suharni ${ }^{2}$ \\ ${ }^{1,2}$ Program Studi Teknik Informatika, Fakultas teknik, Universitas Islam Makassar, Indonesia \\ Email : ${ }^{1}$ ayulestariperdana.dty@uim-makassar.ac.id, 2suharni.dty@uim-makassar.ac.id
}

\begin{abstract}
Abstrak
SMKN 3 Gowa adalah salah satu sekolah yang sudah menerapkan teknologi informasi. Untuk memudahkan kinerja sekolah dalam pelayanan masyarakat, SMKN 3 Gowa mengadopsi sebuah inovasi proses Penerimaan Peserta Didik Baru (PPDB) secara online. Namun dalam pelaksanaannya masih banyak permasalahan yang dihadapi oleh user baik yang bersifat teknis maupun non teknis. Oleh karena itu, diperlukan evaluasi terhadap penerapan PPDB Online guna mengetahui seberapa baik sistem informasi dapat beroperasi. Penelitian ini bertujuan untuk mengevaluasi pelaksanaan PPDB Online menggunakan Innovation and Diffusion Theory (IDT). Terdapat lima karakteristik yang digunakan sebagai kerangka umum faktor penentu diterimanya sebuah inovasi yaitu relative advantage, compatibility, complexity, trialability, and observability. Berdasarkan analisis yang dilakukan diperoleh informasi bahwa dengan adanya penerapan teknologi informasi PPDB online menjadikan proses pendaftaran dalam menyaring nilai lebih transparan dan terpusat. Namun dalam menerapkan sistem informasi tersebut belum sepenuhnya berjalan dengan baik, masih ada berbagai kendala yang dihadapi di antaranya infrastruktur jaringan internet yang kurang memadai, kurangnya pengenalan dan pelatihan secara insentif dan kurang memperhatikan kebutuhan penggunaan terhadap sistem tersebut.
\end{abstract}

Kata Kunci: Innovation and Diffusion Theory (IDT), Online, Penerimaan Peserta Didik Baru (PPDB), SMKN 3 Gowa

\section{Analysis of Information Technology Innovation Adoption Using Innovation and Diffusion Theory (IDT) at PPDB Online SMKN 3 Gowa)}

\begin{abstract}
SMKN 3 Gowa is one of the schools that has implemented information technology. To facilitate school performance in community service, SMKN 3 Gowa adopted an online New Student Admission process (PPDB) innovation. However, in practice there are still many problems faced by users, both technical and non-technical. Therefore, it is necessary to evaluate the application of PPDB Online to find out how well the information system can operate. This study aims to evaluate the implementation of PPDB Online using the Innovation and Diffusion Theory (IDT). There are five characteristics that are used as a general framework for determining the acceptance of an innovation, namely relative advantage, compatibility, complexity, trialability, and observability. Based on the analysis carried out, information was obtained that the application of online PPDB information technology made the registration process in filtering values more transparent and centralized. However, in implementing the information system, it has not fully worked well, there are still various obstacles faced including inadequate internet network infrastructure, lack of introduction and training in incentives and lack of attention to the need for the use of the system.
\end{abstract}

Keywords: Innovation and Diffusion Theory (IDT), Online, New Student Admission Process (PPDB), SMKN 3 Gowa

\section{PENDAHULUAN}

Teknologi informasi semakin banyak digunakan sebagai pendukung proses bisnis dalam suatu instansi. Hal ini disebabkan banyak manfaat yang diberikan dari teknologi informasi sebagai fasilitas suatu instansi perusahaan. Namun dalam praktiknya implementasi teknologi informasi bukan berarti berlangsung tanpa masalah. Dalam penelitian McKinsey menunjukkan bahwa Indonesia masih berada dalam tahap awal digitalisasi dan memiliki paradoks: penghuni digitalnya adalah salah satu yang paling aktif di dunia dan memiliki ekosistem start-up yang dinamis, namun secara keseluruhan tertinggal dalam merangkul manfaat teknologi modern [1]. 
Inovasi dibutuhkan dalam rangka memperbaiki bahkan meningkatkan kualitas, efisiensi dan efektivitas penyelenggaraan pelayanan publik [2]. Salah satu kerangka teori yang dikembangkan untuk mendukung proses adopsi inovasi terkait teknologi informasi adalah Innovation and Diffusion Theory (IDT). Innovation and Diffusion Theory adalah sebuah teori yang menjelaskan bagaimana dan mengapa suatu ide baru diterapkan. Inovasi merupakan ide, praktek, atau objek yang dianggap baru untuk individu atau unit lain untuk diadopsi, sedangkan difusi merupakan proses dimana suatu inovasi dikomunikasikan melalui saluran tertentu dari waktu ke waktu di antara para anggota suatu sistem sosial. Ada lima karakteristik inovasi yang komprehensif, yang sedapat mungkin betul-betul berbeda satu sama lain dan relevan. Kelima karakteristik digunakan sebagai kerangka umum karakteristik utama yang menjadi faktor penentu diterimanya sebuah inovasi yaitu relative advantage, compatibility, complexity, trialability, and observability[3]. IDT telah digunakan di berbagai bidang untuk memprediksi bagaimana dan mengapa suatu inovasi akan berhasil, termasuk pendidikan, komunikasi, pemasaran dan teknologi informasi [4]. Teori ini telah banyak digunakan dalam berbagai penelitian dengan tujuan untuk menilai penerapan teknologi informasi dalam organisasi sebagai sumber daya yang mampu meningkatkan efektifitas kerja.

Salah satu alasan mengapa begitu besar minat terhadap kajian difusi inovasi ini karena ternyata tidak mudah mengusahakan agar ide baru diterima, walaupun sudah jelas kemanfaatannya, di banyak bidang kehidupan ada jarak yang cukup panjang antara pengenalan ide baru dengan pemakainya, banyak inovasi memerlukan waktu yang cukup lama sehingga bertahu-tahun antara saat pertama kali inovasi itu ada dengan saat penerimaannya secara merata di masyarakat, karena itu masalah umum yang sering dihadapi banyak orang dan organisasi adalah bagaimana mempercepat laju penyebaran informasi. Individu yang telah memiliki pengalaman yang berhubungan dengan penggunaan teknologi dapat mempengaruhi kecepatan dalam adopsi sebuah inovasi [5]. Semakin mudah individu melihat hasil sebuah inovasi, maka semakin besar kemungkinan mereka untuk menggunakannya[6].

Sebagaian besar sekolah termasuk Sekolah Menengah Kejuruan melakukan inovasi melalui pemanfaatan Teknologi Infomasi. Pendidikan kejuruan yang baik adalah yang responsive dan antipasif terhadap kemajuan teknologi informasi [7]. SMKN 3 Gowa adalah salah satu yang sudah menerapkan teknologi informasi dalam proses bisnisnya. Teknologi digunakan untuk memudahkan kinerja sekolah untuk melayani masyarakat dalam bidang pendidikan di kabupaten Gowa. Innovation dan Diffusion Theory (IDT) digunakan sebagai dasar eksplorasi penelitian untuk mengevaluasi terhadap PPDB Online Gowa. Tujuan dan manfaat dari adanya PPDB online yaitu masyarakat lebih mengetahui keadaan dan kondisi sekolah yang sesungguhnya sebagai dasar untuk mendaftarkan anak-anaknya bersekolah menentukan sekolah pilihan. Dengan pelaksanaan pengelolaan PPDB online dan terkomputerisasi membuat azas professional, berkeadilan, transparan dan tanpa pungutan liar (pungli) dapat terpenuhi. Hasil dari adanya inovasi PPDB Online yaitu proses penerimaan peserta didik baru berjalan lancar [8].

SMKN 3 Gowa mengadopsi sebuah inovasi untuk mempermudah proses penerimaan peserta didik baru secara online. Proses penerimaan peserta didik baru secara online (PPDB) ini sudah dilakukan empat tahun dalam periode 2018 sampai dengan periode 2021. Namun dalam pelaksanaannya masih banyak permasalahan yang dihadapi oleh user baik yang bersifat teknis maupun non teknis. Evaluasi terhadap PPDB Online dilakukan guna mendefinisikan seberapa baik sistem informasi dapat beroperasi pada organisasi yang menerapkannya untuk memperbaiki kinerja di masa mendatang. Penelitian ini bertujuan untuk mengevaluasi pemanfaatan PPDB Online menggunakan Innovation and Diffusion Theory (IDT) agar dapat dijadikan sebagai bahan pengambil keputusan dan penentu kebijakan bagi SMKN 3 Gowa dalam memperbaiki dan mengoptimalkan peran teknologi informasi khususnya dalam adopsi PPDB Online.

\section{METODE PENELITIAN}

Pendekatan penelitian yang digunakan adalah deskriptif kualitatif. Pendekatan ini merupakan teknik pengumpulan data kualitatif untuk suatu kajian yang bersifat deskriptif [9]. Data berupa gejala-gejala yang dikategorikan maupun dalam bentuk lainnya, seperti foto, dokumen pribadi, catatan lapangan, ucapan dan tindakan responden saat penelitian dilaksanakan dan lain-lain [10]. Penelitian dilaksanakan pada sekolah negeri SMKN 3 Gowa di mana pengumpulan - pengumpulan datanya melalui proses wawancara kepada salah satu pengguna / operator sekolah. Setiap hasil wawancara akan digunakan untuk menunjang hasil penelitian yang dilakukan oleh peneliti.

\subsection{Tahapan Penelitian}

Terdapat beberapa tahapan yang harus dilakukan dalam penelitian ini. Tahapan penelitian dapat dilihat pada gambar 1 di bawah ini. 


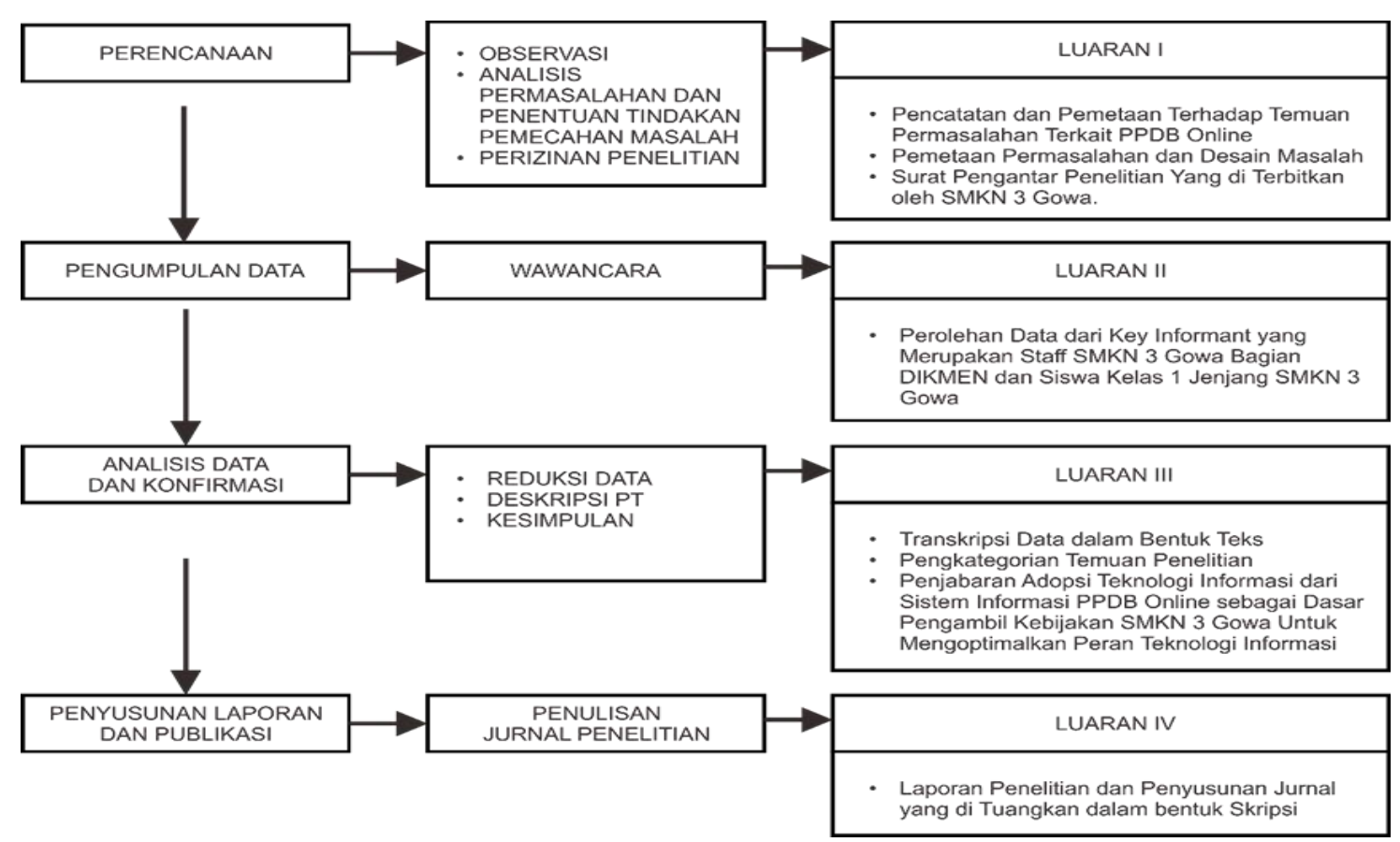

Gambar 1. Tahap Penelitian

Mengacu pada Gambar 1, menjelaskan bahwa terdapat beberapa tahapan yang harus dilakukan dalam penelitian di antaranya:

1). Pada tahap perencanaan langkah pertama yang dilakukan adalah observasi dengan melakukan pencatatanpencatatan pemetaan terhadap temuan permasalah terkait pemanfaatan PPDB Online. Langkah kedua dilakukan analisis permasalahan dan menentukan tindakan pemecahan masalah lalu membuat pemetaan permasalahan dan desain pemecahan masalah. Langkah ketiga, mengurut pertemuan dan penelitian dengan yang diterbitkan oleh SMKN 3 Gowa.

2). Pengumpulan data dilakukan melalui wawancara di mana perolehan data dari key - informant yang merupakan pengguna/operator sekolah negeri SMKN 3 Gowa.

3). Tahap analisis data dan konfirmasi dilakukan reduksi data dengan melakukan data dalam bentuk tes, kemudian mendekripsi data melalui pengkategorian temuan penelitian dan membuat kesimpulan untuk menjabarkan temuan penelitian dan membuat kesimpulan untuk menjabarkan adopsi teknologi informasi PPDB Online sebagai dasar pengambil kebijakan SMKN 3 Gowa untuk mengoptimalkan peran teknologi.

4). Tahap penyusunan laporan dan publikasi laporan dituangkan dalam bentuk jurnal.

\subsection{Model Penelitian}

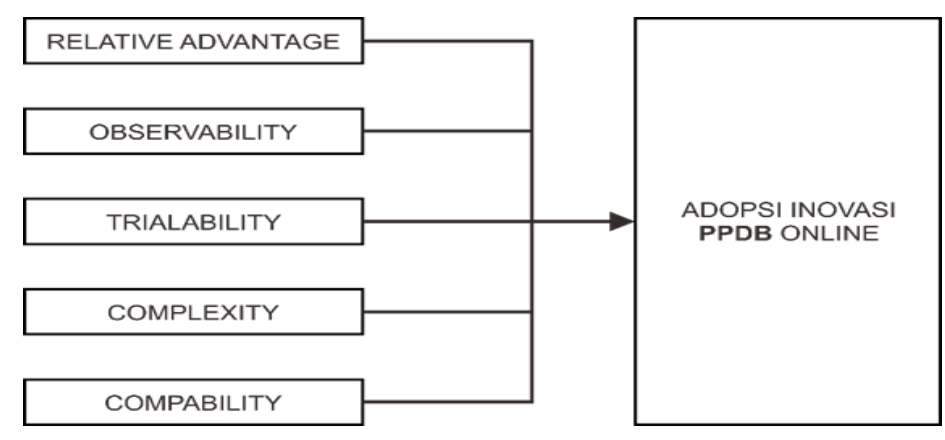

Gambar 2. Model Penelitian

Pada Gambar 2 menunjukkan 5 karakteristik utama yang ada pada Innovation and Diffusion Theory (IDT) yang akan mengevaluasi sebuah inovasi yang diadopsi oleh SMKN 3 Gowa berupa sistem informasi PPDB Online. Adapun bentuk pernyataan dikembangkan adalah pertanyaan terbuka, di mana narasumber bebas 
memberikan pendapat naratif dalam menjawab pertanyaan-pertanyaan yang diajukan. Jenis pertanyaan menyangkut karakterististik dalam IDT, yaitu:

1) Trialability, di mana pertanyaannya mengarah pada pengetahuan tentang sistem yang digunakan serta pengenalan dan pelatihan selama sistem tersebut diterapkan.

2) Compatibility, mengarah pada bagaimana tingkat kesesuaian sistem dengan kebutuhan siswa maupun sekolah dan pandangan terhadap sistem tersebut.

3) Complexity, dalam bentuk pertanyaannya mengarah pada kendala yang sering terjadi selama penerapan sistem tersebut.

4) Observability, mengarah pada sejauh mana hasil yang didapatkan selama penerapan sistem tersebut.

5) Relative Advantage, mengarah pada dampak dan keuntungan yang dirasakan selama menggunakan sistem informasi tersebut.

\subsection{Key Informant}

Tabel 1. Tabel Data Key - Informant

\begin{tabular}{ccccc}
\hline No. & Key Informant & $\begin{array}{c}\text { Umur } \\
\text { (Tahun) }\end{array}$ & Jabatan & $\begin{array}{c}\text { Pengalaman Menggunakan } \\
\text { Internet }\end{array}$ \\
\hline 1 & Arham & 29 & Pengajar & 5 \\
2 & Ari & 31 & Pengajar & 4 \\
3 & Syifa & 36 & Pengajar & 5 \\
4 & Siti & 37 & Pengajar & 4 \\
5 & Thio & 34 & Pengajar & 5 \\
\hline
\end{tabular}

Proses wawancara dilakukan pada sekolah jenjang menengah kejuruan (SMKN 3 Gowa), sekolah yang dianggap cukup memenuhi data yang dibutuhkan dalam mencapai tujuan penelitian. Key Informant dalam penelitian ini adalah pengguna/operator sekolah menengah kejuruan (SMKN 3 Gowa). Wawancara dan observasi penelitian dengan Key Informant dilakukan selama 1 minggu berlangsung di tanggal 24-29 Mei 2021. Dalam melakukan analisis hasil wawancara, maka hal ini dilakukan melalui pandangan dari para narasumber terhadap pernyataan yang diajukan. Oleh karena itu, analisis dilakukan untuk mengacu pada hasil pendapat wawancara yang dilakukan pada Sekolah Menengah Kejuruan (SMKN 3 Gowa) yang dipilih.

\section{HASIL DAN PEMBAHASAN}

Dari hasil wawancara yang dilakukan terhadap masing-masing key informant (operator sekolah) telah diperoleh berbagai temuan terkait tentang peran sistem informasi terhadap proses penerimaan peserta didik baru. Hasil dan pembahasan sesuai dengan lima karakteristik dari pemahaman Innovation and Diffusion Theory (IDT).

\section{Trialability}

Karakteristik Trialability dalam Innovation and Diffusion Theory (IDT) mengacu pada sejauh mana informasi dapat diuji secara terbatas. Pada umumnya sistem informasi PPDB online menurut penuturan para pengguna atau operator yang menjalankan bahan penerimaan peserta didik baru secara online yang kurang lebih 2 tahun terakhir digunakan untuk penerimaan siswa baru berdasarkan nilai ujian nasional. Wawasan tentang teknologi informasi sudah cukup mendalam dan membantu para operator sekolah dapat beradaptasi dalam menggunakan sistem informasi PPDB online. Hanya saja selama penerapannya diperlukan pengenalan dan pelatihan secara insentif sebelum mengoperasikan sistem dengan tujuan agar lebih menguasai dan mengetahui dalam mengoperasikan sistem informasi.

Ari menyatakan bahwa pelatihan secara insentif tentu saja diperlukan karena sistem informasi PPDB online membutuhkan penanganan yang cepat dan setiap tahun mungkin terdapat perubahan sistem maupun inovasi terbaru. Arham, menyatakan bahwa pengenalan dan pelatihan secara intensif sangat dibutuhkan karena sebagai operator yang menangani sistem informasi tersebut sangat membutuhkan prosedur dalam pengoperasikannya. Berdasarkan pernyataan di atas nampaknya bahwa wawasan teknologi informasi dari diri masing-masing operator sebagian besar telah mampu untuk menggunakan sistem informasi penerimaan peserta didik baru. Para operator atau pengguna telah mengetahui sistem informasi PPDB online tersebut dan cara mengoperasikannya. Namun sangat diperlukan adanya pengenalan dan pelatihan yang lebih cepat dengan tujuan agar calon siswa dapat secara cepat mengetahui hasil yang didapatkan.

\section{Compatibility}

Compatibility dalam IDT mengacu pada sejauh mana informasi dianggap konsisten dengan potensi pengguna berdasarkan nilai yang ada, pengalaman sebelumnya, dan kebutuhan. Menurut penjelasan Ari, selama diterapkannya sistem informasi PPDB online, dirasakan belum sepenuhnya sesuai dengan apa yang diharapkan oleh sekolah karena sistem informasi tersebut hanya berdasarkan nilai-nilai ujian para calon siswa dari satuan 
pendidikan sebelumnya. Sedangkan pernyataan dari Thio yang menyatakan bahwa selama sistem berjalan (PPDB Online) mereka hanya mengikuti apa yang diperintahkan oleh Dinas Pendidikan sehingga dalam mengoperasikan sistem informasi tersebut hanya menyesuaikan dari dinas pendidikan sehingga ketika SMKN 3 Gowa menerima reguler dan juga menerima yang akselerasi belum memberikan pengumuman hasil pengayaan tetapi pendaftaran online sudah berjalan. Akibatnya calon siswa dari hasil pengayaan dan pendaftaran online yang didapatkan menjadi banyak sedangkan kuota penerimaan siswa baru pada SMKN 3 Gowa terbatas.

Berdasarkan hasil pengamatan dari penelitian peran sistem informasi PPDB online belum sepenuhnya sesuai dengan kebutuhan pengguna maupun sekolah karena sistem digunakan hanya berdasarkan nilai ujian dari sekolah tingkat nasional, kurangnya tingkat kesesuaian antara kebutuhan siswa dan sekolah menjadikan sistem informasi PPDB online menjadi sangat rumit. Selain itu sistem informasi PPDB online hanya berlaku antara operator dan Dinas Pendidikan, sedangkan calon siswa masih harus ke sekolah memberikan formulir pendaftaran dan operator yang menginput secara online. Thio yang menyatakan bahwa sistem informasi PPDB online yang diadopsi Dinas Pendidikan sebenarnya belum sepenuhnya digunakan secara online karena siswa datang ke sekolah memberikan formulir pendaftaran, kemudian operator yang melakukan pendaftaran secara online ke dinas pendidikan. Pernyataan yang sama dari Siti yang menyatakan bahwa sistem informasi PPDB online belum sepenuhnya. Keseluruhan siswa masih datang ke sekolah untuk melakukan pendaftaran kemudian operator yang memasukkan data ke sistem online dinas pendidikan.

Berdasarkan pernyataan di atas, nampak bahwa sistem informasi PPDB online belum sepenuhnya online karena siswa masih tetap ke sekolah dan memberikan formulir kemudian operator yang menginput ke dinas pendidikan secara online. Penerapan sistem informasi PPDB online masih kurang memperhatikan tingkat kesesuaian dan apa yang dibutuhkan oleh sekolah maupun pengguna. Akibatnya sistem informasi PPDB online yang dilakukan selama ini hanya mengikuti dan menyesuaikan apa yang menjadi tuntunan dari dinas pendidikan. Complexity

Karakteristik Complexity dalam IDT dirasakan tingkat kesulitan end-user dalam pemahaman inovasi dan kemudahan dalam menggunakan perubahan tampilan sistem atau perubahan modifikasi terhadap sistem tidak menghambat para operator sekolah untuk menggunakan sistem informasi PPDB online karena setiap tahun sebelum melakukan pendaftaran online selalu diadakan pelatihan. Selama penerapan sistem informasi PPDB online yang menjadi salah satu kendala yaitu para pendaftar yang dari luar Kabupaten Gowa. Penuturan Syifa yang menyatakan bahwa para calon siswa yang dari luar Kabupaten Gowa masih mendaftar secara manual karena database nilai ujian nasional hanya diperuntukkan bagi calon siswa yang ada di Gowa. Sehingga dari penuturan Thio menyatakan bahwa calon siswa dari Makassar, Maros, Takalar dan yang dari luar kabupaten Gowa masih kesulitan dalam pendaftaran. Kendala lain yang dirasakan oleh para operator selama proses pendaftaran online berlangsung adalah di saat melakukan pendaftaran online secara bersamaan di seluruh sekolah negeri yang ada di Kabupaten Gowa mengakibatkan proses pendaftaran menjadi terhambat karena jaringan internet yang kurang memadai menjadikan proses pendaftaran pada hari pertama dan kedua menjadi lambat memakan waktu yang cukup lama untuk para calon peserta didik yang segera ingin mengetahui hasilnya. Arham menyatakan bahwa yang menjadi kendala utama yaitu jaringan karena online secara bersamaan akibatnya para operator belum dapat memastikan kepada para pendaftar yang sudah mengantri dan menunggu hasil yang didapatkan. Serta penuturan dari Syifa, kendala adalah jaringan karena pendaftaran secara online dilakukan secara bersamaan oleh semua Sekolah Negeri sehingga kecepatannya berkurang. Berdasarkan Penjelasan di atas karakteristik Complexity dalam IDT masih kurang terpenuhi karena pemanfaatan teknologi informasi dalam bidang pendidikan masih belum sepenuhnya sesuai. Kendala yang selalu terjadi selama berjalannya sistem informasi PPDB online yang sudah empat tahun ini khususnya yang dirasakan oleh para pendaftar dari luar kabupaten Gowa masih mengalami kesulitan, karena data pendaftaran yang di luar Gowa masih belum terdaftar di Dinas Pendidikan, akibatnya para operator harus menginput data-data para peserta secara manual satu persatu kemudian setelah datanya sudah lengkap baru dapat melakukan pendaftaran secara online dan sistem informasi PPDB online belum sepenuhnya dan juga jaringan internet yang kurang memadai yang menjadi kendala bagi para operator dalam melakukan pendaftaran secara online.

\section{Observability}

Karakteristik observability dalam IDT mengukur sejauh mana hasil inovasi dapat terlihat oleh orang lain. Pernyataan dari Syifa bahwa hasil yang didapatkan oleh sekolah sudah mencukupi karena calon siswa yang diterima disesuaikan dengan kemampuan akademis mereka karena calon siswa yang diterima berdasarkan nilai tertinggi serta Ari juga menyatakan bahwa hasil yang didapatkan lebih objektif karena sebelum diterapkan sistem informasi PPDB online, masih banyak kecurangan yang dilakukan oleh sebagian pihak. Berdasarkan pernyataan di atas hasil inovasi telah dirasakan oleh setiap sekolah dari penerapan sistem informasi PPDB online dibanding pendaftaran yang dilakukan secara manual. Oleh karena itu, sistem informasi PPDB online telah memenuhi karakteristik dari observability dalam Innovation and Diffusion Theory (IDT). 


\section{Relative advantage}

Karakteristik relative advantage dalam IDT didefinisikan sebagai derajat di mana suatu inovasi dianggap menjadi lebih baik dari sebelumnya. Dengan adanya sistem informasi PPDB online dapat membawa perubahan yang berdampak positif yang sangat dirasakan oleh setiap sekolah. Para operator menyatakan bahwa dengan adanya sistem informasi PPDB online banyak sekali dampak positif yang didapatkan oleh setiap sekolah, salah satunya adalah terbebas dari jalur-jalur curang seperti penuturan dari Syifa yang menyatakan bahwa dengan adanya sistem ini memberikan kesempatan kepada semua calon peserta didik dari berbagai golongan dan juga nilai positif kepada masyarakat karena dengan adanya PPDB online dapat menghindari hal-hal yang negatif karena lebih transparan. Serta penuturan dari Ari yang menyatakan bahwa dampak positif bagi calon siswa adalah lebih percaya diri karena lebih percaya dengan kemampuannya. Melihat Pernyataan di atas terlihat bahwa dengan adanya sistem informasi PPDB online ini membawa pengaruh baik yang lebih besar. Selain itu dapat mengurangi adanya kecurangan yang dilakukan oleh pihak-pihak tertentu karena adanya sistem informasi PPDB online ini menjadikan proses penyaringan para calon siswa baru lebih transparan dan terpusat. Oleh karena itu, sistem informasi PPDB online telah memenuhi karakteristik relative advantage dalam IDT.

Hasil yang didapatkan berdasarkan temuan-temuan yang telah dikemukakan dalam pembahasan di atas maka diketahui bahwa selama menerapkan sistem informasi PPDB online pada Sekolah Menengah Kejuruan (SMK) Kabupaten Gowa, menjadikan proses penyaringan penerimaan siswa baru menjadi lebih transparan dan terpusat sehingga lebih mudah dipantau oleh siapa saja yang memerlukan informasi secara real time. Namun ditemukan beberapa kendala yang dapat menghambat proses penerimaan peserta didik baru secara online, faktorfaktor yang mempengaruhi terbentuknya presepsi pengguna dalam penerapan sistem informasi PPDB online adalah infrastruktur jaringan internet yang kurang memadai, kurangnya pengenalan dan pelatihan secara insentif dan kurang memperhatikan kebutuhan pengguna terhadap sistem tersebut mengakibatkan kebutuhan pengguna terhadap sistem tersebut menjadi semakin rumit dalam penerapannya. Faktor-faktor tersebut mengarah langsung pada persepsi pengguna yang meliputi dampak yang dirasakan dan tingkat penggunaannya.

\section{KESIMPULAN}

Berdasarkan analisis yang dilakukan dengan menggunakan ke lima karakteristik pada Innovation and Diffusion Theory (IDT) dapat disimpulkan bahwa dengan adanya penerapan teknologi informasi PPDB online menjadikan proses pendaftaran dalam menyaring nilai lebih transparan dan terpusat. Namun dalam menerapkan sistem informasi tersebut belum sepenuhnya berjalan baik, masih menemukan berbagai kendala. Kendala yang berpengaruh kuat di antaranya infrastruktur jaringan internet yang kurang memadai, kurangnya pengenalan dan pelatihan secara insentif dan kurang memperhatikan kebutuhan penggunaan terhadap sistem tersebut. Faktorfaktor tersebut mengakibatkan sistem menjadi semakin rumit dalam penerapannya sehingga perlu memperbaiki dan memperhatikan peran teknologi informasi guna mempercepat laju penyebaran informasi di masa yang akan datang.

\section{DAFTAR PUSTAKA}

[1] K. T. Das, K., Gryseels, M., Sudhir, P., \& Tan, "Unlocking Indonesia's digital opportunity," in McKinsey \& Company, 2016, pp. 1-28.

[2] M. Agustini, "Inovasi Pelayanan Publik di Badan Penanaman Modal dan Pelayanan Terpadu (BPMPT) Kabupaten Kubu Raya,” J. Borneo Adm., vol. 10, no. 2, pp. 214-233, 2014.

[3] E. M. Rogers, Diffusion of Innovations, 4th ed. New York: Free Press, 1995.

[4] S. J. H. Shiau, C. Y. Huang, C. L. Yang, and J. N. Juang, "A derivation of factors influencing the innovation diffusion of the OpenStreetMap in STEM education," Sustain., vol. 10, no. 10, pp. 1-29, 2018, doi: $10.3390 /$ su10103447.

[5] S. Setyawan, "Pola Proses Penyebaran dan Penerimaan Informasi Teknologi Kamera DSLR," Komuniti, vol. 9, no. 2, pp. 146-156, 2017.

[6] R. N. Indriyati and M. N. Aisyah, "Determinan Minat Individu Menggunakan Layanan Financial Technology Dengan Kerangka Innovation Diffusion Theory," Nominal Barom. Ris. Akunt. dan Manaj., vol. 8, no. 2, pp. 209-223, 2019, doi: 10.21831/nominal.v8i2.26660.

[7] W. Djojonegoro, Pengembangan Sumber Daya Manusia Melalui Sekolah Menengah Kejuruan. Jakarta: PT. Jayakarta Agung Officit, 1998.

[8] H. Y. Harefa, "Analisis Inovasi Perencanaan Sebagai Strategi Tata Kelola yang Baik di Berbagai Provinsi," J. Stud. Inov., vol. 1, no. 1, pp. 16-21, 2021, doi: https://doi.org/10.52000/jsi.v1i1.3.

[9] W. Yuliani, "Metode Penelitian Deskriptif Kualitatif Dalam Perspektif Bimbingan dan Konseling," vol. 2, no. 2, pp. 83-91, 2018, doi: 10.22460/q.v1i1p1-10.497.

[10] Sugiyono, Metode Penelitian Kuantitatif, Kualitatif dan R\&D. Bandung: Alfabeta, 2010. 